\title{
UNIVERSITYOF
}

FORWARD

THINKING

WESTMINSTER用

WestminsterResearch

http://www.westminster.ac.uk/westminsterresearch

A review of urban consolidation centres in the supply chain based on a case study approach

Allen J, Browne M, Woodburn A and Leonardi J

This is the published version of an article published in Supply Chain Forum: an international journal 15 (4) 100-112 2014. The final definitive version is available via the publisher's website, http://www.supplychain-forum.com/.

(C) 2014 - SupplyChainForum

The WestminsterResearch online digital archive at the University of Westminster aims to make the research output of the University available to a wider audience. Copyright and Moral Rights remain with the authors and/or copyright owners.

Whilst further distribution of specific materials from within this archive is forbidden, you may freely distribute the URL of WestminsterResearch: ((http://westminsterresearch.wmin.ac.uk/)).

In case of abuse or copyright appearing without permission e-mail repository@westminster.ac.uk 


\section{A Review of Urban Consolidation Centres in the Supply Chain Based on a Case Study Approach}

Julian Allen

Planning and Transport Department, the University of Westminster, London

Michael Browne

Planning and Transport Department, the University of Westminster, London M.Browne@westminster.ac.uk

Allan Woodburn Planning and Transport Department, the University of Westminster, London

Jacques Leonardi Planning and Transport Department, the University of Westminster, London

The paper considers how urban consolidation centres (UCCS) can be used in the supply chain to reduce goods vehicle traffic and its associated environmental impacts, while also helping to make supply chains more responsive and efficient and thereby generate commercial benefits. The role of UCCs is presented and the various types discussed. The potential supply chain impacts of UCCs are considered. Case studies of six UCC schemes and trials are included, with their objectives, operational characteristics and impacts compared. The critical success factors associated with UCCs are identified.

Keywords: Urban consolidation centres, freight transport, environmental impacts, cities

\section{Introduction}

This paper addresses the use of urban consolidation centres (UCCs) to improve the efficiency of freight transport in cities and thereby to reduce its traffic and environmental impacts. UCCs can assist in improving vehicle load consolidation, as well as offering the opportunity to use electric ${ }^{1}$ and other alternatively-fuelled goods vehicles instead of diesel to make deliveries from the UCC resulting in reduced $\mathrm{CO}_{2}$ and a reduction in other emissions (Nitrogen Oxides, CO, Particulate Matter).

The paper begins with a literature review of the role and potential benefits of UCCs including a consideration of the supply chain implications that arise when they are established. The second section of the paper adopts a case study approach to consider six UCC trials and operations in Europe. Experiences from each of the case studies are identified and assessed in order to establish the main factors that that influence and determine their success. The paper concludes with reflections on the lessons learned from the assessment.

\section{Literature review of UCC developments and supply chain impacts}

A UCC is a logistics facility that is situated in relatively close proximity to the urban area that it

\footnotetext{
1. UCCs are typically located on the edge of small and medium-sized cities and within the urban area for larger cities. As a result this results in shorter final delivery trips than is often the case when urban delivery is made from a regional distribution centre-for electric vehicles where range remains an issue this shorter average trip distance makes their use more feasible.
} 
serves. Goods destined for the urban area are delivered to the UCC by transport operators whereupon they are sorted and consolidated for delivery to the final destination by the UCC operator. This final delivery often uses environmentally-friendly vehicles such as electric and gas-powered goods vehicles, and in some cases electrically-assisted cycles (see for example Allen et al, 2012; Browne et al, 2005; Di Bartolo, 2012; Lewis and Fell, 2012).

By improving the load factor of goods vehicles making deliveries in congested urban locations and by performing well-organised multi-leg vehicle journeys, UCCs reduce the distance travelled per unit of product delivered in urban areas (see Figure 1). In addition, UCCs also help to reduce greenhouse gas emissions and local air quality pollutants associated with these journeys (both through reductions in the total distance travelled, and through the use of low emission vehicles (Browne et al., 2007). The total kerbside time and space occupied by vehicles making onstreet deliveries can be reduced through the consolidation effects of using UCCs, further reducing the impact of freight operations on traffic congestion. Other social and environmental advantages can include noise reductions through the use of quieter vehicles,

\section{Figure 1 \\ Urban distribution systems with and without an urban consolidation centre}

\section{Without an urban consolidation centre}

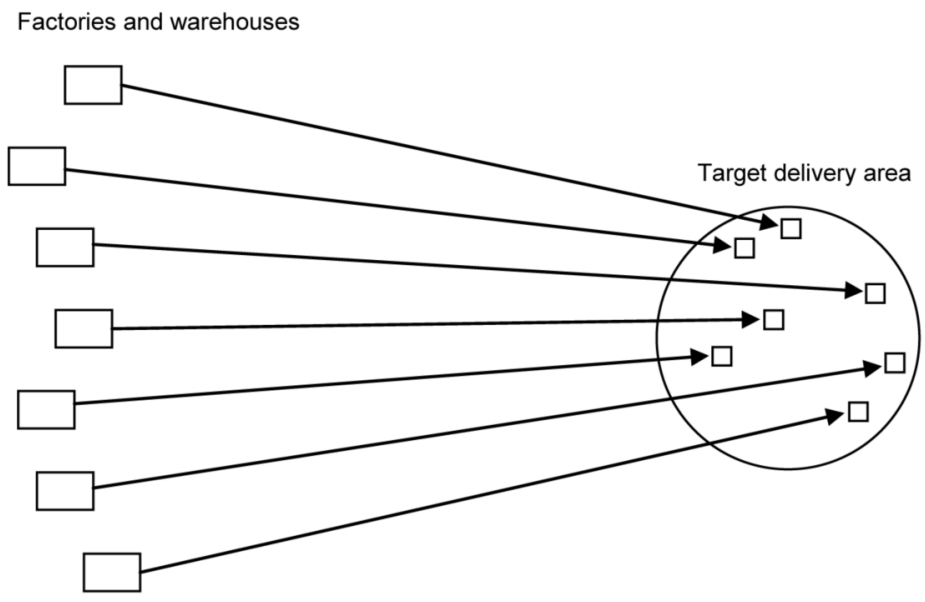

\section{With an urban consolidation centre}

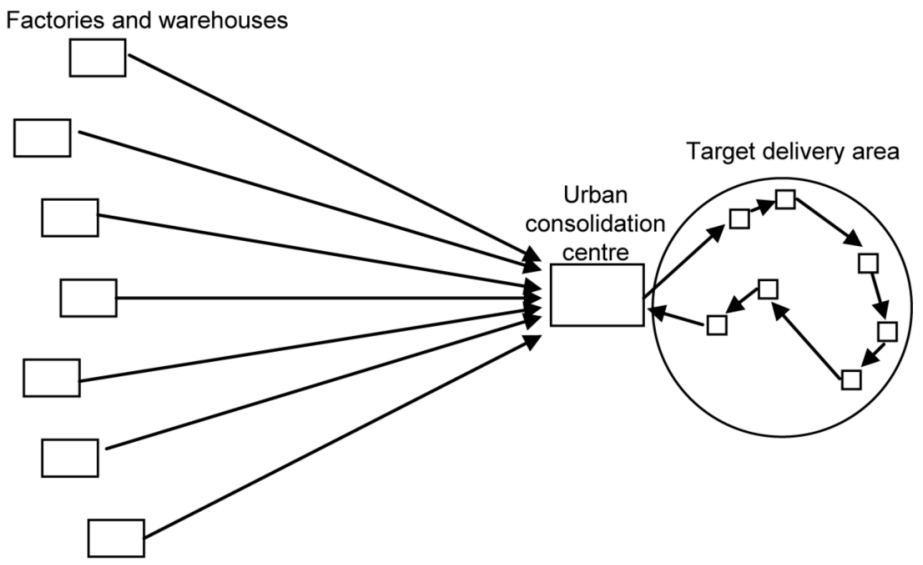

reductions in conflicts between goods vehicles and other road users and greater pedestrian safety (Gonzalez-Feliu and Morana, 2008; WSP, 2008). Although operators could change to quieter vehicles for all delivery operations the advantage of a UCC is that the transport operation can be tailored to fit with the special requirements of the urban environment. Therefore rather than having to operate an entire fleet of vehicles that are suitable for urban delivery and operator may be able to take advantage of the UCC in order to optimise their fleet disposition and investment.

Research into UCCs as a means by which to reduce the impacts of urban freight transport initiative started in the early 1970s and has gained increasing levels of interest during the last decade (see for example Browne et al., 2005; Danielis and Marcucci, 2008; Institut für Seeverkehrswirtschaft und Logistik, 2005; McKinnon, 1998a; McKinnon, 1998b; van Duin et al., 2010). Under this respect both applied and theoretical research have discussed the role that road pricing (rp) might have in facilitating the adoption of UCC in freight distribution. For a review of the first type of literature please refer to Zunder and Ibanez (2004) and for the second to Marcucci (2004).

Three major categories of UCC have been defined: i) UCCs that serve all or part of an urban area, ii) UCCs that serve large sites with a single landlord such as a shopping centre, airport, or hospital, and iii) UCCs that serve major construction sites. The first two types of UCC are usually associated especially with retail products, as well as office products, and occasionally food supplies for restaurants and cafes, while the third type of UCC handles building materials. The first type of UCC is often used to serve urban locations with spatial features such as narrow streets, historic layouts, and limited unloading facilities, and are therefore usually initially proposed by city authorities, primarily on traffic and environmental grounds, and may receive 
some form of public support when they are initially developed. In the case of the second type of UCC, the interest usually stems from developers and owners desire to maximise retail space by minimising on-site storage and the need for multiple delivery bays (WSP, 2008). The third type of UCC is usually instigated by the site developer or main construction contractor to reduce project costs, or can be made mandatory through the planning permission process as a result of traffic concerns (in some cases the site developer provides initial financial support for the UCC and may meet some of the running costs). The argument for support for UCCs is discussed later in the paper and has received attention elsewhere (Allen et al., 2012)

Some goods flows will not benefit by passing through a UCC. For example, fully-loaded vehicles making deliveries to a supermarket are already efficiently consolidated at regional distribution centres and there would be no benefit in terms of urban vehicle kilometres by insisting that these vehicles were to deliver via a UCC. However, in some instances (see the case studies in section 4) there are overriding management or security reasons justifying why all flows are managed via a UCC.

Each of the three types of UCC defined in the previous section can either offer relatively basic consolidation and delivery services or offer a wider range of valueadded logistics activities. These include: off-site stockholding, inventory management, consignment unpacking, preparation of products for display (including hanging, ironing and labelling), goods return and waste collection services. UCCs can also be used to offer community collection and delivery point facilities (for other consumer and business products), while home delivery operations can also be operated from the UCC. Figure 2 illustrates the range of logistics and pre-retail activities that can be carried out by a UCC and the potential benefits of these activities. By offering such valueadded logistics services, the UCC operator can enhance revenues, differentiate themselves in the market place, and build relationships with users (Grant, 2005). However, the use of a UCC can result in some transport companies losing their link to the

\section{Figure 2 \\ Range of potential logistics and pre-retail activities at UCC and possible benefits}

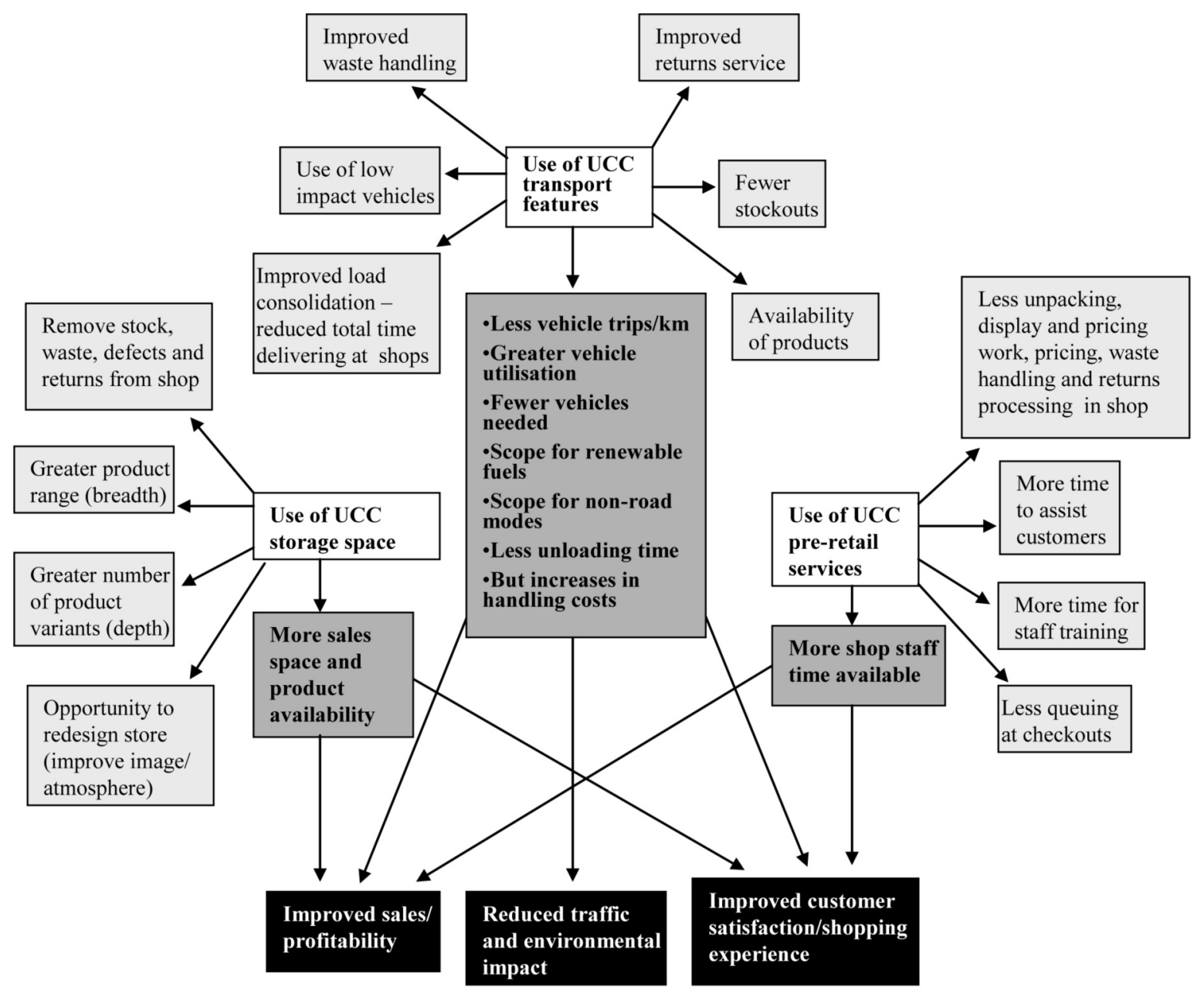

KEY:

UCC features

Operational benefits

Outcome

Economic, social and environmental effects 
final receiver of the goods (as they now deliver only to the UCC) and there can be negative responses to this change in the business relationship as it is perceived as a threat.

By offering stockholding services to users, a UCC can help to reduce delivery lead times, and improve product availability and the customer service provided by users. Space at the receiving establishment can be freed up for other activities that are more productive or profitable, such as retailing, which is likely to be particularly beneficial when space is at a premium or expansion is desirable. Inventory monitoring, linked to in-store systems, can be provided to increase the visibility of the supply chain, also leading to better product availability and service levels (and related increases in sales or site productivity). Other pre-retailing activities can help to reduce time and space requirements at the destination location.

UCCs can therefore offer benefits to all supply chain partners. The shippers and logistics companies dropping their loads at the UCC benefit by avoiding the need to enter congested urban areas and queuing to make deliveries, thereby saving vehicle time and costs. Those receiving goods from the UCC can benefit in terms of delivery reliability, product availability, reductions in the need for on-site storage space and opportunities to enhance productivity and sales in core activities through the freeing up of space and personnel. UCC operations provide either a new business opportunity or the potential for business expansion to those providing these services. Developers and site owners can reduce the delivery bay requirements and thereby free-up this space for other, more profitable activities. The inhabitants of the urban area benefit from the reduction in goods vehicle traffic and reductions in vehicle pollution, noise, and greater pedestrian safety that UCCs can provide.

\section{Case studies of six UCC implementations}

This section contains case studies of six UCC schemes established in Europe in recent years. Table 1 shows the basic details of these six schemes. The sample comprises a range of UCC types, a mix of sectors and examples of optional and compulsory scheme participation. This includes two UCCs that serve all or part of an urban area, two UCCs that serve a major site with a single landlord (retail outlets in an airport and a shopping centre), and two construction project UCCs. For each UCC, the objectives, operational characteristics, and impacts are examined.

\section{London Heathrow Retail Consolidation Centre}

\section{Background and objectives}

Retail development within Heathrow airport increased dramatically over the decade up to 2000 , but the capacity of road and unloading infrastructures was not expanded accordingly. Problems included traffic congestion on airport roads and at loading bays, and lengthy and unpredictable delivery times. These issues, together with growing environmental pressures and the potential requirements of the planned Terminal 5, led to a re-examination of the supply system serving retail and catering outlets in Terminals 1-4.

A study reviewed the various retail delivery options. It concluded that the specific conditions would be best met by an urban consolidation centre through which all deliveries should pass with the exception of newspaper deliveries, cash and valuable items which should continue to be delivered directly to retail outlets. A four-month trial was established in March 2000 in which the Heathrow Airport Limited (HAL) (the owner of Heathrow airport) contracted the logistics provider DHL Supply Chain to operate a consolidation centre, vehicle fleet and related goods reception and inventory

Table 1

Key characteristics of the UCCs

\begin{tabular}{|c|c|c|c|c|c|c|c|}
\hline Centre & Location & UCC type & Product type & $\begin{array}{l}\text { Trial or fully } \\
\text { operational }\end{array}$ & $\begin{array}{l}\text { Use of electric } \\
\text { vehicles? }\end{array}$ & Current status & Terms of use \\
\hline London Heathrow & London, UK & Airport & Retail & $\begin{array}{l}\text { Trial then fully } \\
\text { operational }\end{array}$ & Partial & Active & Compulsory \\
\hline Meadowhall & Sheffield, UK & Shopping centre & Retail & $\begin{array}{l}\text { Trial then fully } \\
\text { operational }\end{array}$ & No & Active & Voluntary \\
\hline Bristol (Broadmead) & Bristol, UK & Part of urban area & Retail & $\begin{array}{l}\text { Trial then fully } \\
\text { operational }\end{array}$ & Partial & Active & Voluntary \\
\hline Monaco & Monaco & Entire urban area & $\begin{array}{l}\text { Retail plus other } \\
\text { consumables }\end{array}$ & $\begin{array}{l}\text { Trial then fully } \\
\text { operational }\end{array}$ & Partial & Open & Compulsory** \\
\hline $\begin{array}{l}\text { London Construction } \\
\text { Consolidation Centre }\end{array}$ & London, UK & Construction & $\begin{array}{l}\text { Construction } \\
\text { materials }\end{array}$ & Trial & No & Closed* & Compulsory ** \\
\hline Hammerby & $\begin{array}{l}\text { Stockholm, } \\
\text { Sweden }\end{array}$ & Construction & $\begin{array}{l}\text { Construction } \\
\text { materials }\end{array}$ & $\begin{array}{l}\text { Trial then fully } \\
\text { operational }\end{array}$ & No & Closed & Compulsory \\
\hline
\end{tabular}


management systems. Eight retailers with a total of 40 retail outlets across the four terminal buildings participated. Results showed a 66 per cent reduction in vehicle deliveries. Operations started in May 2001 (Department for Transport, 2002).

\section{Operational aspects}

A 2,300 sq m warehouse with cold store was established at Hatton Cross (2.5 km from Terminal 4) employing 20 operational and clerical staff. Deliveries by suppliers to the centre were subject to security checks, and then put into roll cages and sealed ready for dispatch to the retail outlets. By 2002 the delivery fleet consisted of three tractor units and three box-van trailers with tail-lifts. Two trailers had dual compartments and were fitted with refrigeration to cater for chilled and frozen food deliveries. The delivery vehicles are also used to collect and remove empty roll cages, recyclable packaging waste, such as cardboard and plastic. In 2007 DHL introduced electric vehicles to the consolidation centre fleet (Avison, 2007a).

A new consolidation centre was developed in 2006 to cope with the growing space demands, higher product throughput and planning requirements for Terminal 5 . This new centre is also based approximately $2.5 \mathrm{~km}$ from the airport and operates 24 hours a day, 7 days a week. Incoming deliveries are cross-docked onto the centre's vehicles and deliveries made to airside and landside stores from which other consolidation centre staff deliver orders to each retail outlet. These staff can also stock shop shelves and carry out pre-retailing services such as pricing and ticketing.

By 2009 the consolidation centre was handling deliveries to 323 retail and catering outlets, pubs and restaurants based in the airport (DHL, 2009). The consolidation centre operation employs approximately 100 people (Avison, 2007b).
All retail and catering concessions operating at Heathrow airport use the consolidation centre as part of their rental agreement. Retail consolidation was a prerequisite for the planning permission to build Terminal 5 . It must therefore accommodate ambient, chilled and frozen goods. The UCC is funded by the airport operator and the outlets using its services; it receives no public subsidy.

\section{Impact assessment and outcome}

The Heathrow retail consolidation centre reduces vehicle deliveries to outlets in the airport by approximately 80 per cent (Bastien, 2007). It has been estimated that in 2008 these consolidated deliveries resulted in a saving of $218,000 \mathrm{~km}$ (DHL, 2009). This reduction in total distance travelled together with the use of an electric vehicle has been estimated to result in a $158,000 \mathrm{~kg}$ reduction in $\mathrm{CO} 2$ emissions (DHL, 2009).

\section{Meadowhall Consolidation Centre}

\section{Background and objectives}

The Meadowhall Consolidation Centre was established in 2003 by British Land (the owners of the Meadowhall shopping centre) and was initially operated by Exel Logistics until 2006 but is now run by Clipper Secure Logistics. It serves retailers within the shopping centre, which is located adjacent to the M1 on the edge of the city of Sheffield. The shopping centre attracts 25 million visitors per year The UCC is located on the perimeter of the shopping centre site. It is a voluntary scheme, so there is no compulsion for retailers to channel their goods through it, nor are there any penalties for, or restrictions on, deliveries that are made directly to retailers' premises.

The Meadowhall UCC scheme has a strong supply chain focus, aiming to add value to the retailers' trading experience through achieving operational cost savings and greater buying power. The specific objectives are to: i) permit retailers to increase their sales floor area (by removing the need for storage area within the retail space); ii) help retailers to maximise sales through stock availability and product range; ii) help retailers to reduce freight transport and staffing costs; iii) allow retailers' staff to focus on dealing with customers; and iv) reduce or prevent theft of stock (Clipper Logistics, 2007).

\section{Operational aspects}

For retailers using the UCC, vehicles bringing goods for them deliver to the UCC instead of the store. The UCC can meet retailer's requirements for goods by making deliveries within two hours of an order for product being made by a retailer. The UCC consists of 3,000 $\mathrm{sq} \mathrm{m}$. of storage space (Steers, 2009). Six employees work at the UCC providing the warehousing and transport services, with extra staff at peak times when necessary. Two 7.5 tonne goods vehicles are operated from the UCC for deliveries to stores (Clipper Logistics, 2007). The UCC has secure dedicated retailer caged areas as well as flexible racking bays for basic storage. The UCC operates seven days per week and is used by approximately 180 retailers (Steers, 2009).

In addition to consolidation and delivery services the UCC also offers a range of other value-added services. These include storage service such as providing an off-site stockroom; stock room management; retail furniture and fixtures storage; and peak and seasonal storage facilities (Steers, 2009). Pre-retail services include: hanging goods after unpacking; relabelling of goods ready for shop floor; pressing services; RFID/security tagging; and label printing. The UCC can also handle store recalls and returns, and provide staff training facilities. Retailers are able to pick and choose the services that suit their needs.

The UCC operates on a commercial basis and receives no public subsidy. It generates revenue from the consolidation and delivery 
services provided, as well as the value-added pre-retail services available (Clipper Logistics, 2007).

\section{Impact assessment and outcome}

The operator claims that the cost of using the UCC can be recovered by retailers through store cost savings, increased sales and reduced product losses. Examples include: a baker that achieved a 10 per cent increase in sales of confectionery through increasing product ranges; a fashion retailer that experienced increases in sales for three days prior to Valentines Day due to receiving replenishments twice per day from the UCC; another fashion retailer that reduced theft of goods by 70 per cent by using storage space in the UCC rather than in the store; and a food and non-food retailer that enjoyed a 4 per cent increase in sales by using the seasonal storage facilities available at the UCC. Another retail outlet that does not open until 10:00 had previously been forced to accept its delivery at 06:00, meaning that staff had to be provided at that time to receive the goods. By using the UCC, the delivery could still be made in the early morning, but not forwarded to the retail outlet until staff were available in-store, thus saving wage costs (Clipper Logistics, 2007).

In addition to the sales turnover benefits to the retailers using the UCC, it has also reduced the number of vehicles delivering to Meadowhall shopping centre. The number of vehicle deliveries to stores using the UCC has been reduced by approximately 65 per cent (Newing, 2008).

\section{Bristol Urban Consolidation Centre}

\section{Background and objectives}

The urban consolidation centre in Bristol was originally established as a trial in an EU-funded CIVITAS project. The objectives of the trial were to reduce goods vehicle activity in the central retailing area (Broadmead), thereby helping to relieve traffic congestion, improve air quality and minimise conflict between vehicles at loading areas/delivery bays. The trial was also intended to provide suppliers and retailers with improved logistics services, removing the need for suppliers to send their vehicles into central Bristol, increasing delivery reliability and offering a range of value-added services for such as pre-retailing, remote storage, and packaging and waste collection. The consolidation centre and delivery operations have been operated by DHL since it opened in 2004.

\section{Operational aspects}

The trial commenced in May 2004. It has since become a permanent UCC scheme. Retailer participation in the UCC scheme is voluntary. The area served has been extended from Broadmead to the new Cabot Circus Centre retail development which opened in 2008 adding 40 per cent to the retail floorspace in the area. Also in 2008, new pedestrian areas were introduced and tighter loading time restrictions imposed (05:00-08:00 for the main pedestrian area of Broadmead). This has encouraged more retailers to make use of the consolidation centre (START, 2008). The catchment area comprises over 400 retail outlets, approximately 70 of which currently use the consolidation scheme (Minihane, 2009).

The consolidation centre has a floorspace of $500 \mathrm{sq}$. m. and is located on an industrial estate on the north western edge of Bristol, close to both the M4 and M5 motorways, 15 kilometres (25 minutes travel time) from Broadmead district, (Minihane, 2009). Two delivery vehicles are operated from the centre, an 18 tonne diesel-powered vehicle with a Euro IV engine and a 9 tonne electric goods vehicles (Hapgood, 2009). The centre handles retail goods only and operates six days per week (Bastien, 2007). The local transport authority allows UCC vehicles to access a bus lane to and from the city centre on a trial basis to cut delivery times and improve reliability (Hapgood, 2009).
In addition to the consolidation and delivery services, other valueadded services are provided at the UCC including collection of waste cardboard and plastic for recycling, and pre-retailing activities.

The development and trial phase of the UCC from 2002-2006 was funded through the EC CIVITAS VIVALDI project. Some subsequent financial support has been provided by Bristol City Council. Approximately 40 per cent of UCC costs are covered by charges paid by users (Hapgood, 2009). Public funding is planned to reduce progressively over time. This is intended to be achieved through signing up new retailers to use the service, and selling more value-added services to users. In addition, the UCC is to be offered to non-retail end users, and the scope of UCC services can also be expanded to include council deliveries (Minihane, 2009). The use of public funds to support the operation has reduced over time as more retailers have joined the scheme. In addition, the centre now also serves Bath - a historic city located $20 \mathrm{~km}$ from Bristol (DHL, 2013).

\section{Impact assessment and outcome}

The UCC has resulted in a 77 per cent reduction in vehicle deliveries to participating retailers. This is equivalent to a total reduction of approximately $\quad 10,000 \quad$ vehicle deliveries per annum, with a saving of 250,000 vehicle kilometres. It is estimated that the UCC scheme yields annual savings of approximately 30 tonnes of $\mathrm{CO} 2$, $1,000 \mathrm{~kg}$ of NOx, and $30 \mathrm{~kg}$ of PM10. In addition 20 tonnes of cardboard/plastic are collected and recycled (Hapgood, 2009; Minihane, 2009).

Feedback from retailers has been positive, with 94 per cent stating that they would recommend the UCC service to another retailer, and a majority of retailers report that they are saving more than 20 minutes per delivery. As a consequence, 38 per cent say that this enables their staff to spend more time with customers, and 45 per cent state that staff morale has 
improved and stress levels have reduced (Minihane, 2009). Retailers generally seem to appreciate the improved service and cost reduction opportunities offered by channelling deliveries through the UCC. Detailed financial operating costs are not available for the UCC as it is run commercially by DHL. However, the steady reduction in public funding support and the continued existence of the UCC suggest that revenue from the users ahs grown over time and that profits are considered at least satisfactory from a business perspective.

While the scheme has been successful in operational terms since it was initiated it has taken time to enhance its commercial viability and this has mainly been built on additional retailers joining the scheme and identifying new sources of revenue from preretailing activity.

\section{Monaco Urban Consolidation Centre}

\section{Background and objectives}

The Principality of Monaco is an extremely small sovereign state located on France's Mediterranean coast. It comprises the old city of Monaco, Monte Carlo (which is the main residential and resort area), and the port area, together with several other wards. It has a total area of 1.95 sq. km. and a population of approximately 30,000 , making it one of the most densely populated countries in the world.

The Monaco UCC was established in 1989. It is owned by the principality, which manages it as a public service (City Ports, 2005). On a day-to-day basis the UCC is operated by a private company. The Chamber of Commerce and Industry and ADEME (the French Energy Agency) are also partners of the UCC scheme (Interface Transport, 2003; Patier, 2005). The main aims of the Monaco UCC are to reduce traffic congestion and disruption caused by deliveries in the extremely dense urban area, as well as improving the efficiency of goods distribution.

\section{Operational aspects}

The company operating the UCC has been given a monopoly over the municipal freight depot. In addition, goods vehicles over 8.5 tonnes gross weight are banned from entering Monaco, except for temperature controlled, some other perishable goods, some indivisible loads (e.g. fuel delivery) and removals. If vehicles over 8.5 tonnes have goods that need to be delivered, they have to deliver these goods to the UCC. The UCC operator then makes the final delivery of these goods on their own vehicles.

Vehicles less than 8.5 tonnes gross weight can enter the principality during the following time periods: 07:45-08:15, 11:30-12:30, and 13:4514:45 (City Ports, 2005). At times when these lighter vehicles are not allowed to enter the principality, they can instead be parked in loading/unloading areas, while the drivers make deliveries and collections on foot (Interface Transport, 2003; Patier, 2005; Patier, 2006).

There are two logistics platforms for the Monaco scheme: a UCC and a PAL (Logistics Activity Park). The UCC is a 1,300 sq. m. platform located on the south west edge of Monaco. It was established in 1989 when the scheme was introduced and is located in Fontvielle, an industrial and commercial ward in the principality that was reclaimed from the sea in the 1970s. It has eight employees, and operates six vehicles (three 3.5 tonne vehicles, one 7.5 tonne vehicle, and one electric light duty vehicle). The PAL which established in 2002 is a dedicated 20,000 sq. m. storage area located in the logistics park of Nice by the Monaco principality. It provides a range of services including customs clearance, storage, order picking, delivery, and collection. This is located approximately 20 minutes drive from Monaco (Interface Transport, 2003; Patier, 2006). In 2004, approximately 4,800 goods vehicles made deliveries at the UCC and PAL. The number of items handled was approximately 24,000 (Patier, 2006).
The costs of the UCC are shared between the Monaco municipality (which provides financial aid and free warehouse space to the UCC operator), the UCC operator (which provides drivers and handling staff as well as the UCC vehicles), and the receivers and deliverers of goods (who pay for deliveries, which contributes towards the cost of operating the UCC) (Interface Transport, 2003).

\section{Impact assessment and outcome}

The Monaco scheme has resulted in a more efficient urban delivery system for the principality. Even though the Monaco scheme mostly makes use of diesel-powered goods vehicles, it has still resulted in approximately 25 per cent reductions in $\mathrm{CO} 2$ emissions from goods vehicles and 25-30 per cent reductions in local air pollutants from goods vehicles (Patier, 2005). In addition it has been estimated that the Monaco scheme has also resulted in a 30 per cent reduction in vehicle noise pollution; 38 per cent reduction in traffic congestion; and 42 per cent reduction in the space used by vehicles for deliveries (Patier, 2005).

\section{London Construction Consolidation Centre}

\section{Background and objectives}

A two-year trial project referred to as the London Construction Consolidation Centre (LCCC) operated from 2005 to 2007 during the construction of major new office blocks in London. The LCCC was a 5,000 sq. m. facility located in South Bermondsey, approximately five kilometres south of the City of London. Its objective was to serve four major construction sites in the City of London. The LCCC was intended to reduce the number of deliveries going directly to the construction sites and thereby reducing traffic congestion and vehicle emissions. The main reason for carrying out this LCCC project was to assess the potential benefits that such a scheme could bring (Transport for London et al., 2008). The construction sites were active throughout the operational life of 
the LCCC thereby providing a useful test of the operational benefits of the centre.

\section{Operational aspects}

Contractors working on the four construction sites placed orders for their material requirements with their suppliers in the normal way, but instructed that the delivery was made to the LCCC, not the construction site. Contractors then placed a delivery order with the LCCC for the materials they required. This was assembled at the LCCC and delivered to the sites. Approximately a sixth of all the deliveries requested from the LCCC by the construction sites were needed within less than 24 hours notice (i.e. on a just-in-time basis). This level of service would probably have been difficult to achieve if deliveries were made directly to site by suppliers. The delivery from the LCCC to the construction sites consolidated numerous contractors' orders onto each vehicle.

As well as delivering construction materials to the sites, the vehicles operating from the LCCC also provided up to ten days of storage. It also collected recyclable packaging and unused materials and brought them back to the LCCC. This was then recycled, returned through the supply chain for re-use or collected by a waste operator. It is important to note that some supplies continued to be sent directly to the construction sites rather than via the LCCC. These included aggregates, structural steel, ready-mix concrete, escalators and furniture, all of which were usually delivered as a full vehicle load.

The LCCC employed 16 staff and had a fleet of six delivery vehicles. This comprised four flatbed rigid vehicles (ranging from 18 to 26 tonnes gross weight), one 7.5 tonne gross weight curtain-sider rigid vehicle and one 3.5 tonne gross weight van.

The cost of the trial was met by a partnership of private developers / construction companies and Transport for London (TfL), the public organisation responsible London's transport system. Some of the costs of the LCCC were passed on to the individual building contractors (Transport for London et al., 2008). However, details of the costs passed to companies were not published.

\section{Impact assessment and outcome}

Operational targets were set for the performance of the LCCC. These are shown in Table 2 alongside the operational performance actually achieved. The performance targets were equalled or surpassed. Overall, the LCCC trial was therefore judged to have been an operational success as all targets were met or exceeded. The targets for the LCCC were established in consultations between TfL, the developers and the organisation Constructing Excellence that provided independent advice about new opportunities to improve construction logistics processes.

For those materials delivered via the LCCC, it is estimated there was a $60-70$ per cent reduction in the number of vehicles delivering to the four construction sites. Taking account of all deliveries from suppliers, there was a reduction of approximately 40 per cent in total vehicle deliveries to the Unilever House building site. This was considered the best managed site as it had the lowest proportion of direct deliveries (Transport for London et al., 2008).

The vast majority of deliveries from the LCCC to construction sites were made in rigid goods vehicles, eliminating the use of articulated goods vehicles for site delivery, and significantly reducing the use of vans. The LCCC achieved an average reduction in supplier journey times of two hours (compared with them delivering direct to site (this included unloading time). The response of receivers to these improvements was captured by means of qualitative interviews and was not subject to rigorous tests relating to their willingness to pay. This can be considered a lost opportunity for the trial.

Ninety-seven per cent of the materials delivered from the LCCC to the sites were of the correct type and quantity and were delivered within 15 minutes of the scheduled time. In addition, productivity of the labour force on the construction sites increased by up to 25 minutes per person-day as a result of the delivery reliability from the LCCC (Transport for London et al., 2008).

Negative impacts included some work scheduling problems at the construction sites caused by a

\begin{tabular}{lcc}
\hline Key Performance Indicator & Target & Achieved \\
\hline Reduction in freight journeys & $40 \%$ & $\begin{array}{c}60-70 \% \text { of journeys via LCCC } \\
40 \% \text { of journeys to construction site }\end{array}$ \\
\hline $\begin{array}{l}\text { Reduction in journey time of supplier } \\
\text { deliveries to contractors }\end{array}$ & $30-60$ minutes & 120 minutes \\
\hline Delivery reliability & $97 \%$ & $97 \%$ \\
\hline
\end{tabular}

Source: Transport for London et al., 2008. 
lengthening of the order lead times for products channelled through the LCCC. There were also a few instances of incorrect components being sent from the LCCC to the sites and items being misplaced at the LCCC.

The LCCC trial was therefore judged to have been a success. While the original centre closed down at the end of the trial period, a $7,500 \quad \mathrm{~m} 2$ replacement construction UCC opened shortly afterwards in east London. This new UCC is operated by Wilson James, the operator of the trial UCC, on a commercial basis, highlighting the viability of the concept. It is serving a number of major construction projects, such as the redevelopment of Barts and the Royal London Hospital (Wilson James Ltd, 2008).

\section{Hammerby Construction Consolidation Centre}

\section{Background and objectives}

The Hammerby construction consolidation centre was active from 2001 from 2004, the duration of the main construction phase of a redevelopment project in the former docklands and industrial area of Stockholm. Although the redevelopment was not completed until 2010, the main materials movements were concentrated in the three years in which the site was open. The development comprises 8,000 new apartments as well as other facilities (e.g. schools, commercial premises).

The objectives of the UCC were to: i) achieve an 80 per cent reduction in the number of small volume, direct deliveries (i.e. of less than 4 pallets) to the site through consolidation; ii) reduce traffic congestion within the construction site; iii) enhance living conditions for new residents in the area; iv) improve the working environment; and v) reduce energy use and emissions.

\section{Operational aspects}

The UCC was located adjacent to the construction site, and acted as a focal point for all delivery vehicles coming to the site. Use of the UCC was compulsory for all these delivery vehicles. If flows had not been coordinated, 700 tonnes of materials would have been delivered to the site by 400 vehicles each day. By using the UCC, flows of materials were consolidated for 22 different delivery areas within the site, with two trips per day being made from the UCC to each delivery area. An operator was contracted to run the UCC and the delivery vehicles, as well as the associated administrative issues. Ten people were employed by the UCC and five goods vehicles and three fork lift trucks were used. The UCC offered 3,500 sq. m. of storage indoors and a further 4,000 sq. m. outside. An internet-based calendar was developed so that contractors could log the scheduled arrival times of their deliveries, to try to improve the visibility of vehicle delivery times. A traffic coordinator also helped to minimise traffic congestion impacts within the site (Ottosson, 2005; Wilson James Ltd and Mace Ltd, 2003).

Originally, 95 per cent of the project's funding came from the City of Stockholm authorities (including EU funds through the CIVITAS Trendsetter programme). Once operational, charges were raised, so that the public share of funding was reduced to 40 per cent. It has been suggested that, had the UCC operated for a longer period of time, or should a new one be required in the Stockholm area, it should be possible for it to operate without direct public funding (Ottosson, 2005). The rationale for this suggestion is that the efficiency of the UCC grew during its operation and valuable lessons were learned that would be available for any further initiatives in this field.

\section{Impact assessment and outcome}

The five UCC project objectives identified above were fulfilled, although the 80 per cent reduction in small volume, direct deliveries was achieved only at peak times. The UCC achieved significant operational and environmental benefits. The reduced vehicle activity (down by approximately 60 per cent) and reduced vehicle queuing times (down by approximately 90 per cent) combined to provide an estimated 90 per cent reduction in $\mathrm{CO} 2$ emissions. Vehicle load factors were increased from approximately 50 to 85 per cent as a result of the UCC (Ottosson, 2005). Analysis of the construction process suggests that the UCC was instrumental in achieving on-time completion of new buildings, and there were fewer problems than normal with regards to damaged or stolen goods.

\section{Conclusions}

This paper has assessed the role that can be played by UCCs in reducing urban freight transport activity. This is achieved through improvements in vehicle load factors and by performing wellorganised multi-leg vehicle journeys, which lead to reductions in the distance travelled per unit of product transported in urban areas. UCCs also facilitate greater use of electric and other alternatively-fuelled goods vehicles which emit less CO2 and other, noxious gases and reduce vehicle noise. Thereby UCCs can be used to bring about reductions in the traffic and environmental impacts of urban freight. As previously explained, due to the location of UCCs in the city, the journeys from them are usually short and are therefore more feasible for use of electric vehicles than many other freight trips.

In addition to these traffic and environmental benefits, the implementation of a UCC facilitates the provision of a wide range of value-added logistics services activities that can lead to improvements in supply chain efficiency and responsiveness and business performance (as well as cost reductions). These include: reductions in delivery lead times, improvements in product availability and customer service, improvements in the visibility of the supply chain, reductions in stock losses, and the ability to 
maximise retailing space and hence increase sales. All supply chain partners can potentially benefit from the introduction of a UCC. UCCs should therefore be viewed as one potentially important innovation in helping to achieve greater sustainability in urban freight transport in both economic and environmental terms.

The case studies presented in the paper have helped to describe the various types of UCC that can be established and their attributes. The assessment of the case studies illustrates that a range of organisational, operational and financial issues have to be addressed in establishing a successful UCC scheme. These include: the potentially high set up costs (and sometimes high operating costs) that need to be recovered; contractual issues concerning legal responsibility for goods; the loss of the direct interface between suppliers and customers (which could possibly deter some potential users); and the relatively low rates of product throughput in the early stages of UCC start-up.

The case studies have identified two factors that are likely to be critical to the success of a UCC scheme. The first is the level of demand. Sufficient UCC users and product throughput is required to drive down the costs per unit handled thereby making the UCC competitive with traditional urban distribution systems. The second is the sharing of UCC costs and benefits between the various supply chain parties involved in the scheme. Although the UCC may result in total benefits that outweigh total costs (taking into account commercial, traffic, social and environmental impacts), each party must be prepared to share these costs and benefits fairly if the scheme is to succeed (Browne et al., 2005; TTR, 2007; TTR 2010).

These two factors are more easily addressed in the case of UCCs that serve major sites with a single landlord and construction project UCCs as in these cases a single commercial party is typically responsible for financing the UCC. That party either enjoys all the benefits of the UCC scheme or has leverage to recover some of the costs from the other beneficiaries.

The case of UCCs that serve all or part of an urban area is more problematic. In these cases the decision of users to participate in the UCC is typically a voluntary one and there is no single private body responsible for financing the UCC or exploiting the benefits. Instead there are typically many business users, as well as a local authority that is keen to encourage the implementation of a UCC in its efforts to reduce traffic and environmental impacts. In the short-term the local authority can implement accompanying policy measures that encourage greater use of the UCC, such as allowing UCC vehicles access to bus lanes, or imposing tighter vehicle access or loading restrictions in the UCC catchment area. As new users are attracted to the UCC and product throughput increases, the level of any public support, which is often required in the initial stages, can be reduced as financial contributions from users increase.

Many UCC trials and schemes have been initiated by the public sector with the key objective of reducing the negative impacts of urban freight transport. However, in order to have a long-term future it is important that a strong business case for the UCC exists. This is likely to require a greater focus on the value-added services that can be providing and the role that these can play in achieving a more efficient and lower cost logistics operation, as well as facilitating an increase in retail sales and/or site productivity. This is reflected in the case studies presented of London Heathrow and Meadowhall UCCs. Both of these schemes were led by the private sector and continue to operate successfully without public subsidy. Such examples can provide important insight into the types of logistics services and service levels required to ensure that UCCs play an important and beneficial role in supply chains.

\section{References}

Allen, J., Browne, M., Woodburn, A. and Leonardi, J., (2012), The role of urban consolidation centres in sustainable freight transport, Transport Reviews, 32 (4), 473-90.

Avison, R., (2007a), DHL hopes to expand airport consolidation centre, Road Transport.com, 24 July 2007. Available from: http://www.roadtransport.com/ Articles/2007/07/24/127981/DHL-hopesto-expand-airport-consolidationcentre.htm [Accessed 6 October 2014]

Avison, R., (2007b), Making consolidation centres work, Road Transport.com, 27 July 2007. Available from: http://www.roadtransport.com/ Articles/2007/07/27/128022/Makingconsolidation-centres-work.htm [Accessed 6 October 2014]

Bastien, O., (2007), An Introduction to Retail Consolidation Centres, presentation to the West London Freight Quality Partnership, 10th January 2007.

Browne, M., Woodburn, A., Sweet, M., and Allen, J., (2005), Urban Freight Consolidation Centres, Report for Department for Transport, London: University of Westminster. Available from: http://www.freightbestpractice. org.uk/urban-freight-consolidationcentre-report [Accessed 6 October 2014]

Browne, M., Woodburn, A., and Allen, J., (2007), Evaluating the potential for urban consolidation centres, European Transport, 35, 46-63.

City Ports, (2005), City Ports Project: Interim Report, Regione Emilia-Romagna. Available from: http://mobilita. regione. emiliaromagna.it/allegati/pubblicazioni/ quaderni-servizio-pianificazione/ quaderno_7.pdf [Accessed 6 October 2014]

Clipper Logistics, (2007), The ARC at Meadowhall, presentation made by Clipper Logistics at the Logistics Consultants Day, 23 February 2007.

Danielis R. and Marcucci, E., (2008), The potential demand for a urban freight consolidation centre, Transportation, 35 , 269-284.

Department for Transport, (2002), Heathrow Airport Retail Consolidation Centre, Good Practice Case Study 402, Energy Efficiency Best Practice 
Programme. Available from:

http://www.freightbestpractice.org.uk/h eathrow-airport-retail-consolidationcentre [Accessed 7 October 2014]

DHL, (2009), DHL wins major contract extension for Heathrow Consolidation Center, press release 16 November 2009, DHL. Available from: http://www.dpdhl.com/en/media_relations/press_rele ases/2009/dhl_wins_contract_extension _for_heathrow_consolidation_center.ht ml [Accessed 7 October 2014]

DHL, (2013), DHL helps Bristol and Bath councils free up the high street, press release 18 September, DHL. Available from: http://www.dhl.co.uk/en/press/ releases/releases_2013/local/091813.ht ml [Accessed 7 October 2014]

Di Bartolo, C., (2012), ECOLOGISTICS Parma: consolidation and last mile delivery of goods in an open and competitive city logistics scheme (Italy), ELTIS case study. Available from: http://www.eltis.org/index.php?id=13\&l ang1=en\&study_id=3455

[Accessed 7 October 2014]

Gonzalez-Feliu, J., and Morana, J., (2010), Are City Logistics Solutions Sustainable? The Cityporto case, Territorio Mobilità e Ambiente, 3 (2), 5564.

Grant, D. B., (2005), The Transaction Relationship Dichotomy in Logistics and Supply Chain Management, Supply Chain Forum: an International Journal, 6 (2), 3848.

Hapgood, T., (2008), Broadmead Freight Consolidation Scheme, presentation made 28 July 2008.

Hapgood, T., (2009), The Importance of Freight Management and the Role of Urban Consolidation Centres, paper presented at Seventh Transport Practitioners Meeting: Ideas and Reality, 13-15 July, University of Reading.

Interface Transport, (2003), Evaluation environnementale du Centre de Distribution Urbaine de marchandises de Monaco, Final report for ADEME (ref: Marché n0203013).

Lewis, A. and Fell, G., (2012) Southampton Sustainable Distribution Centre Viability Study, report for Southampton City Council by Mott MacDoanld and TTR. Available from: https://www.southampton.gov.uk/Image s/MMTTR\%20Final\%20Report \%20-
$\% 20$ App $\% 20 \mathrm{~F} \% 20$ Redacted_tcm 46343597.pdf [Accessed 7 October 2014]

Marcucci, E., (2001), "Road pricing: old beliefs, present awareness and future research paths", International Journal of Transportation Economics, vol. XXVIII, pp. $49-80$.

McKinnon, A., (1998a), International Review of Urban Transhipment Studies and Initiatives, Report prepared for the Retail and Distribution Panel of the UK Government's Foresight Programme, Edinburgh: Heriot Watt University. Available from: http://www.sml.hw.ac. uk/downloads/logisticsresearchcentre/ UKTranshipINT.pdf [Accessed 4 May 2011]

McKinnon, A., (1998b), Urban Transhipment: Review of Previous Work in the UK, Report prepared for the Retail and Distribution Panel of the UK Government's Foresight Programme, Edinburgh: Heriot Watt University. Available from: http://www.sml.hw.ac. uk/downloads/logisticsresearchcentre/ UKTranshipUK.pdf [Accessed 7 October 2014]

Minihane, E., (2009), Bristol Consolidation Centre, presentation made at Chartered Institute of Logistics and Transport Seminar 14th October 2009.

Newing, R., (2008), Transport: Finding better ways to deliver the goods, The Financial Times, 8 October.

Ottosson, M., (2005), Evaluation report New Concepts for the Distribution of Goods (WP 9), Report No 2005:7, External Deliverable No 4.3e, Trendsetter project. Available from: http://www.eukn.org/dsresource?object id=24142 [Accessed 7 October 2014]

Patier, D., (2005), Follow up of environmental and energy consumption effects from some French experimentations, presentation at COST 355 meeting, WG1 "Changing Behaviour for a more sustainable transport system", 19 May 2005, Arcueil.

Patier, D., (2006), New concept and organisation for the last mile: The French experiments and their results, chapter in Taniguchi. E. and Thompson, R. (2006) Recent Advances in City Logistics, Elsevier.

START, (2008), City of Bristol: Access Management and Priority Measures, START project factsheet.
Steers, P., (2009), Retail Consolidation Centres, presentation at The Role of Consolidation Centres in Sustainable distribution, CILT seminar, 14th October 2009, Meadowhall Centre Ltd.

Transport for London, Bovis Lend Lease, Constructing Excellence, Stanhope, Wilson James, and the University of Westminster, (2008), London Construction Consolidation Centre: Final Report, London: Transport for London. Available from: http://www .tfl.gov.uk/cdn/static/cms/documents/lc cc-final-report-july-2009.pdf [Accessed 7 October 2014]

TTR, (2007), South London Freight Consolidation Centre Feasibility Study: Final Report - Executive Summary, report prepared on behalf of South London Freight Quality Partnership, TTR. Available from: http://www.centrallondonfqp.org/app/download/12244777/SL FCC-Feasibility-Report-ExecutiveSummary.pdf [Accessed 7 October 2014]

TTR, (2010), Freight Consolidation Centre Study: Main Report, Prepared for Department for Transport, TTR. Available from: http://www.ttr-ltd.com/downloads /pdf/DfTFreightConsolidationCentreStu dy-04112010.pdf [Accessed 7 October 2014]

van Duin, R., Quak, H. and Muñuzuri, J., (2010), New challenges for urban consolidation centres: A case study in The Hague, The Sixth International Conference on City Logistics, Procedia Social and Behavioral Sciences, 2, 61776188.

Wilson James Ltd., and Mace Ltd., (2003), Logistics Consolidation Centre: Stockholm, Sweden, Site Visit Report September 2003, Wilson James.

Wilson James Ltd., (2008), Personal communication from representative of Wilson James Ltd, July 2008.

WSP, (2008), Freight Consolidation and Remote Storage, BCSC Educational Trust. Available from: http://resources.bcsc. org.uk/publications/download.asp?id=1 94\&pub=FreightConsolidation2008.pdf [Accessed 7 October 2014]

Zunder, T. and Ibanez, J.N., (2004), Urban freight logistics in the European Union, European Transport \Trasporti Europei, 28, 77-84. 


\begin{abstract}
About the authors
Julian Allen is a Senior Research Fellow in the Planning \& Transport Department at the University of Westminster, where he is involved in research and teaching activities relating to freight transport and logistics. His current research interests are urban freight transport, the impact of manufacturing and retailing techniques on logistics and transportation systems and the history of freight transport.

Michael Browne is Professor of Logistics and directs freight transport and logistics research at the University of Westminster. He leads the University's input to the Volvo Research and Educational Foundations Centre of Excellence for Sustainable Urban Freight Systems. He is on the US Transportation Research Board's Urban Freight Transportation Committee as well as representing the University on many other external committees and boards. He chairs the Central London Freight Quality Partnership and is a visiting professor at the University of Gothenburg.

Allan Woodburn is a Principal Lecturer in Freight and Logistics in the Planning \& Transport Department at the University of Westminster. He is involved in a wide range of teaching, research and consultancy activities in the field of freight transport, both within the UK and internationally. Allan completed his doctorate examining the role for rail freight within the supply chain in 2000 . Since then, his main research focus has been on rail freight policy, planning and operations, focusing specifically on efficiency and sustainability issues.

Jacques Leonardi is a Senior Research Fellow in the Planning \& Transport Department, University of Westminster. His research specialities are related to urban freight transport, supply chain energy and carbon footprinting, global logistics, surveys and survey methods, new technologies, and policy impact evaluation. Recent work includes research for the following projects: Green Logistics, BESTFACT, SMARTFUSION, Luxembourg UDC, and Cargocycles.
\end{abstract}

\title{
COMMENTS
}

by Emmanuelle Mœsch

Paca-Logistique Cluster

Through detailed case studies and a synthetic analysis, this article gives the reader an insight on different types of urban consolidation centres (UCC) and key elements of their success.

\section{Literature review}

The literature review offers a clear and concise definition of urban consolidation centres and their expected benefits. It also points out the main lever of UCCs to reach set goals on congestion, emissions, noise, etc., which is the improvement of load factors and a better organization of the journeys, without trying to adopt a prescriptive view on elements such as the vehicle size which should be used. This analysis allows for various schemes to be considered a potential solution.

The three categories of UCCs defined in the article have the advantage of being both precise and easily comprehensible. However, it would be even better to have an estimate of the respective share of these different categories in UCCs already implemented. Also, it would be justified to define sub-categories and select more case studies to represent the UCCs serving all or part of an urban area, as this category seems to represent a larger proportion of existing UCC, and also covers a wide range of schemes that can differ greatly in organisation, cost structure, stakeholder involvement and areas covered.

Although its synthetic aspect is a notable quality of this article, some additional elements could also be mentioned in the literature review. With the growing interest of research in the UCC the discussion of the potential role of road pricing is mentioned; it would also be interesting, most of all for business and institutional actors, to mention other public policies which might favour UCCs - some of which are mentioned in the case studies. Many of these are more easily implemented than road pricing: restriction to certain zones and/or at certain times, use of bus lanes, reserved loading / unloading areas, etc. Along with other stakeholders mentioned in the literature review, local public authorities also benefit from improved urban freight distribution, which is why they are often "keen to encourage the implementation of a UCC" and willing to engage in such measures.

The question of public policy leads to another debate, which is not mentioned directly in this paper: the role of public institutions. The general trend today is towards a limitation of public spending, and public support is presented here as in other papers as necessarily short-term. Nevertheless, there is still a margin for local authorities to act upon their priorities, and in some situations the improvement of urban freight distribution can be considered a public priority needing direct support from local authorities. This is particularly the case when its negative externalities (in various 
forms of pollution) can damage urban heritage, and more so when they contribute to put citizens' health, and eventually life, under threat.

\section{Case studies}

One of the main insights of this article is the level of assessment of the case studies. Evaluation information for UCC cases are often lacking, either because UCC initiators may not share it or have not conducted a solid evaluation altogether. Going further, clarification on the level trustworthiness of the cases' evaluations would make this even more valuable.

When new UCC projects come into consideration, the question of the business case is essential, as mentioned in the conclusion. Most of all, the cost structure raises many questions: what is the cost, who should pay, and how much? These in turn lead to more questions : who will benefit from the UCC, who can afford to pay, and how much? The article does mention which stakeholders participate financially in the operations of the UCC, but does not always indicate the comparative share nor does it mention prices for offered services. Unfortunately the details of the cost structures of each scheme, not to mention the evaluation of its success globally lack in most studies, which is probably explained by confidentiality issues on economic data. More details on this aspect would be highly valuable for new projects.

For future research - Elements of interest for professionals

The case studies provide detailed description of some technical aspects: size of the warehouse, number of vehicles, numbers of delivery, etc. This available data could be the base for a crosscutting analysis, providing general ratios for each type of UCC on information such as storage space and number of vehicles required depending on the number of shops served, etc.
The article highlights the importance of additional valueadded services for UCC, both in effectively enhancing the global supply-chain and attracting more users. If the corresponding information is available, another work could delve more on these services and most of all their evaluation: are the provided services actually used, and to what level? Are the users satisfied by these services?

Another subject which could be explored in further work is the level of involvement of stakeholders, and the process adopted to obtain this involvement, most of all in the case of UCCs serving all or part of an urban area.

Finally, this article like most of the current literature focuses on assessment of existing experiences, and finding within these the key characteristics of success. Due mainly to economic reasons, logistics is not a field where risktaking in new business models is widespread : thus it would be interesting for research to design new schemes and assess their potential strengths and weaknesses in a prospective view.

\section{Data availability}

The case studies are a valuable illustration of concrete cases and more detailed than most publications; but this points out an issue on available data inherent to the research on the subject.

First, let's consider the perception of what can be considered a UCC established in "recent" years. From a professional point of view, given the rapid evolution of the industry and its legal and technological context, a recent experience would be one established in the latest 4 to 5 years at the latest.

Also, a great majority of recent literature regarding UCCS is based on prior research, second hand information or information provided by communication documents.

A wider study of UCCs, building enough cases to provide wide data, would be interesting. Such work was done in 2005 (Browne et al), and more recently focusing on some regions (Gonzalez et al., 2013). Still, most of the literature (including the present article) globally points to a lack of up to date data, both in width and depth. To constitute this data would imply important field investigation, with the difficulty of finding the right interlocutor, let alone have access to documents. However, such database is needed to further research, knowledge, and operational implementations in the field of efficient UCC schemes. 